\title{
Model Integrating Fleet Design and Ship Routing Problems for Coal Shipping
}

\author{
Qingcheng Zeng and Zhongzhen Yang \\ Transport and Logistics College, Dalian Maritime University, 116026,Dalian, China \\ Qingcheng Zeng, Zhongzhen Yang, zqcheng2000@tom.com
}

\begin{abstract}
In this paper, an integrated optimization model is developed to improve the efficiency of coal shipping. The objective is (1) to determine the types of ships and the number of each type, (2) to optimize the ship routing, therefore, to minimize the total coal shipping cost. Meanwhile, an algorithm based on two-phase tabu search is designed to solve the model. Numerical tests show that the proposed method can decrease the unit shipping cost and the average ship delay, and improve the reliability of the coal shipping system.
\end{abstract}

Keywords: coal shipping, fleet design, ship routing, tabu search.

\section{Introduction}

Coal is one of the most important energy resources used in China. With the rapid economic development, the demand for coal is rapidly increasing in recent years. Due to the uneven distribution of coal sources, a large quantity of coal must be transported from west and north to east and south in China by railway and shipping. Therefore, optimization of shipping is the fundamental and key element to ensure the efficiency and reliability of coal transportation system. And significant improvement of fleet operation can be achieved by proper ship routing and scheduling.

In this paper, we will consider optimization of coal shipping from a set of outbound ports to demand ports. The problem involves determining the type of ships, the number of each type, and the optimal ship routing. Kim [1] developed a prototype optimization-based decision support system for the ship owner's scheduling problem in bulk trade. Fagerholt [2] developed a model to decide the optimal fleet size for liner shipping problem. Christiansen [3] studied a combined inventory management problem and a routing problem with time windows for ammonia transportation. Liua [4] studied the coal shipping and blending problems for an electric utility company. Fagerholt [5] considered a real ship scheduling problem as a multi-ship pickup and delivery problem with soft time windows. Persson [6] proposed an optimization model and a solution method to determine how to route a fleet of ships and the planning of which products to transport in these ships.

To ensure the integrated optimization, the ship routing and fleet design problems should be considered simultaneously. But most of the existing literatures studied the two problems respectively. In this paper, a model integrating fleet design and ship routing is developed. To solve the model, two-phase tabu search (TS) algorithm is 
designed. And a real shipping planning problem is given as an example to illustrate the validity of the model and algorithm.

\section{The Fleet Design and Ship Routing Problem}

The background of this paper is a real problem that involves developing a new ocean shipping system for SEC (Shenhua Energy Company, the largest coal supply company in China). In the system, the coal produced by SEC is transported by railway to the outbound ports: Huanghua, Tianjin, and Qinhuangdao first, then by shipping to demand ports. Because of the natural constraints, the maximal ship capacity allowed by Huanghua port is 50,000 ton. Besides, Huanghua port is owned by SEC, to ensure the full utilization of the port, it is given priority in the ship routing. Therefore, if a ship's capacity exceeds 50,000 ton, it must be loaded at Huanghua port first, then reloaded at Tianjin or Qinhuandao, and discharged at demand ports lastly. Meanwhile, the type of ships used determines whether to reload or not and thus influences the ship routing. Therefore, optimization of coal shipping problem can be divided into two phases: the first phase is to determine the ship type; the second phase is to optimize the routing based on the ship type, and determine the reloading strategy.

Let $P_{T}$ be the total set of ports and $K$, indexed by $k$, be set of available ship types to be routed and scheduled. $O \in P_{T}, D \in P_{T}$ denote the set of outbound and demand ports respectively, and $s$ denote Huanghua port; $Q_{d}$ is coal traffic destined for port $d ; c_{i j d}^{k}$ denotes the total unit shipping cost per ton from outbound port $i$ to demand port $d$ through reloading port $j$ using ship type $k$; $C A P^{k}$ is the capacity of ship type $k$, and $C A P_{i}$ is the maximal ship that port $i$.

If coal demand of port $d$ is transported by ship type $k, y_{d}^{k}=1$, and 0 , otherwise. $x_{i j d}^{k}=1$ if ship of type $k$ runs from port $i$ to port $d$ through reloading port $j$, and 0, otherwise. $x_{i i d}^{k}=1$ denotes that ships of type $k$ run from port $i$ to port $d$ directly. Thus, the integrated model can be formulated as follows:

$$
\begin{gathered}
\text { Min } \sum_{i, j \in O, d \in D, k \in K} c_{i j d}^{k} Q_{d} y_{d}^{k} . \\
\text { s.t. } \sum_{k \in K} y_{d}^{k}=1 \forall d \in D . \\
\sum_{j \in O} x_{i j d}^{k}=1 \quad \forall d \in D, \forall i \in O, \forall k \in K . \\
x_{s j d}^{k}=1 \quad \forall j \in O, \forall d \in D . \\
x_{i s d}^{k}=0 \forall i \in O, \forall d \in D .
\end{gathered}
$$




$$
\begin{gathered}
x_{s j d}^{k}\left(C A P^{k}-C A P_{s}\right) \geq 0 \quad \forall k \in K, \forall d \in D, \forall j \in O . \\
y_{d}^{k}\left(C A P_{d}-C A P^{k}\right) \geq 0 \quad \forall k \in K, \forall d \in D . \\
x_{i j d}^{k}, y_{d}^{k}=1, \text { or } 0 \quad \forall k \in K, \forall d \in D, \forall i, j \in O .
\end{gathered}
$$

The objective function (1) is to minimize the total coal transportation cost. Constraints (2) ensure that every demand port is served by only one type of ship. Constraints (3) ensure that each ship is reloaded no more than once. Constraints (4) guarantee that all the ships must be loaded at Huanghua port first. Constraints (5) and (6) determine that reloading only happens on the condition that $C A P^{k}>C A P_{s}$. Constraints (7) ensure that the capacity of the ship served to demand port $d$ does not exceed the maximal loaded ship the port allows. (8) is variable constraints.

\section{Solution Procedures}

To reflect the inter-relation between the fleet design and ship routing, a tabu search (TS) algorithm is designed to solve the model. Fig.1 shows the general process of this algorithm: The two-phase approach integrates two levels of decision making. In the first phase of the algorithm, one TS is performed to determine a good ship type design. For each ship type design obtained during the first phase, the other TS is ran to obtain the reloading scheme, then calculate objective function, namely, the total shipping cost, so as to influence the TS in the first phase. The feedback and reciprocity between the two phases form the optimization scheme.

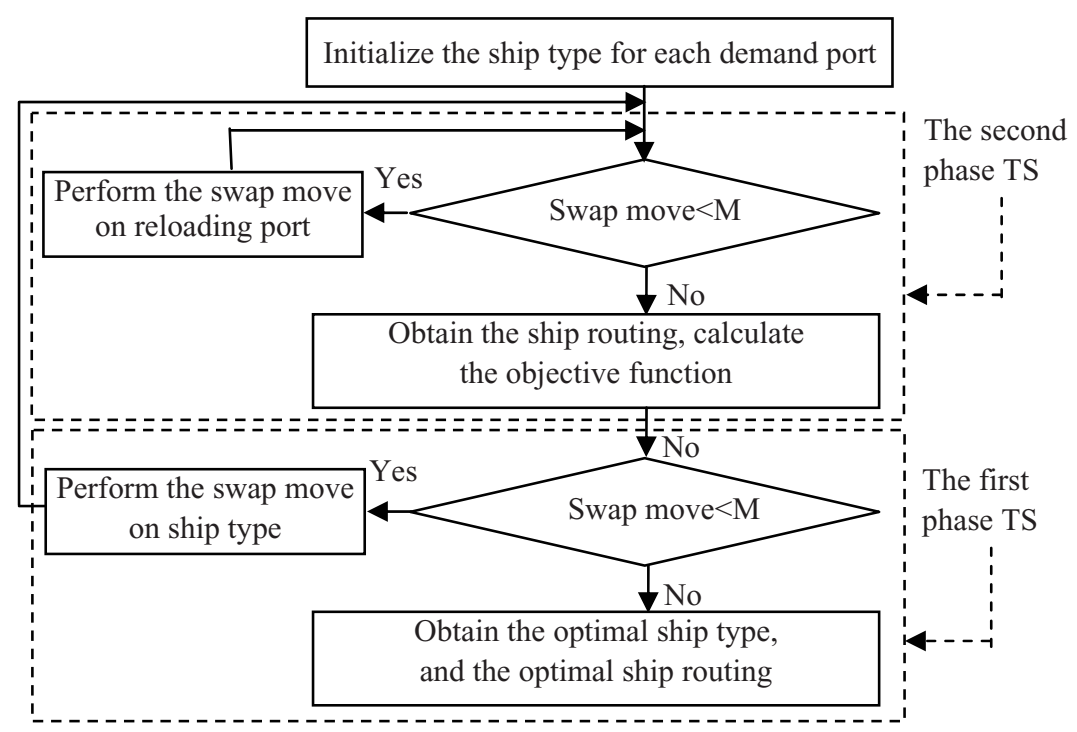

Fig. 1. Two-phase TS algorithm for coal shipping model 


\section{Numerical Tests}

Numerical tests are used to illustrate the validity of the model and its algorithm. The maximal passing capacity of the three outbound ports is 100,000 ton; therefore, all the ship types we select are less than 100,000 ton. Results are shown as Table1. From Table1, we can compare the proposed method with the current status of SEC. We can find that the unit shipping cost decreases $21.01 \%$, and the average ship capacity increases $37.39 \%$. This indicates that the coal shipping cost can decrease by using larger ships. At the same time, the number of voyages decreases $34.4 \%$ due to the increase of the ship capacity. And also, the Average Delay in Huanghua Port decreases $26.87 \%$, this is because the decrease of the ships berthing in Huanghua port.

Table 1. Comparison of the results by our method with the current status

\begin{tabular}{llll}
\hline Heading level & Our model(1) & Current status(2) & $((1)-(2)) /(2)$ \\
\hline Unit cost (RMB/ton) & 124 & 157 & -0.2101 \\
Average ship capacity (ton) & 40,450 & 29,441 & 0.3739 \\
The number of voyages & 1,740 & 2,650 & -0.3434 \\
Average delay in Huanghua(hour) & 49 & 67 & -0.2687 \\
\hline
\end{tabular}

\section{Conclusions}

In this paper, a model integrating fleet design and ship routing for coal shipping is developed. Numerical results indicate that the proposed method can decrease the unit shipping cost, reduce the ship delay in port, and improve the efficiency and reliability of the coal shipping system. For SEC, it can improve the coal shipping efficiency by large-scaled ships. However, this is restricted by the port passing capacity, especially the demand ports in south China. Therefore, for coal shipping system of China, the efficiency can be improved by reasonably planning the ports layout, and increasing the passing capacity of the demand ports.

\section{References}

1. Kim Si-Hwa, Lee Kyung-Keun: An optimization-based decision support system for ship scheuling. Computers \& Industrial Engineering 33 (1997) 689-692.

2. Fagerholt Kjetil: Optimal fleet design in a ship routing problem. International Transactions in Operational Research. (1999) 453-464.

3. Christiansen Marielle: Decomposition of a combined inventory and time constrained ship routing problem. Transportation science 33, (1999) 3-16.

4. Liua Chiun-Ming, Sherali Hanif D. A coal shipping and blending problem for an electric utility company. Omega 28 (2000) 433-444.

5. Fagerholt Kjetil: Ship scheduling with soft time windows: An optimization based approach. European Journal of Operational Research 131(2001)559-571.

6. Persson Jan A: Shipment planning at oil refineries using column generation and valid inequalities. European Journal of Operational Research 163 (2005) 631-652. 